\title{
El concepto de fascismo \\ y las dictaduras militares: \\ Agustín Cueva y los debates de teoría política \\ en los años setenta y ochenta
}

\section{The Concept of Fascism and Military Dictatorships: Agustín Cueva and the Debates on Political Theory in the Seventies and the Eighties}

Andrés Tzeiman*

RESUMEN: Este trabajo pretende llevar a cabo una recuperación del debate que se suscitara en la bisagra de los años setenta y ochenta entre la intelectualidad crítica latinoamericana acerca de la conceptualización de las dictaduras militares que en ese entonces atravesaban la región. Con ese fin, el artículo parte de la figura del sociólogo ecuatoriano Agustín Cueva, quien no sólo participó activamente de aquellas controversias, sino que también mantuvo intercambios con otros intelectuales latinoamericanos, especialmente en revistas o publicaciones de la academia mexicana (como la Revista Mexicana de Sociología o Cuadernos Políiticos). Los debates en cuestión giran fundamentalmente en torno a la pertinencia teórico-política de la categoría de fascismo para caracterizar a las dictaduras autóctonas de aquella época, y aquí nos concentramos en las intervenciones de intelectuales como Atilio Boron, René Zavaleta y Ruy Mauro Marini.

PalabRas Clave: Agustín Cueva; Dictaduras; América Latina; Fascismo.

ABSTRAC: This work intends to carry out a recovery of the debate that arose in the hinge of the seventies and eighties in Latin American social sciences about the conceptualization of the military dictatorships that present in the region at that time. To that end, the article is based on the figure of the Ecuadorian sociologist Agustín Cueva, who not only actively participated in those controversies, but also maintained exchanges with other Latin American intellectuals, especially through the publications of the Mexican Academy (such as the Revista Mexicana de Sociología or Cuadernos Políiticos). The debates in question revolved fundamentally around the theoretical-political relevance of the category of fascism to characterize the autochthonous dictatorships of that time, and here we concentrate on the interventions of intellectuals such as Atilio Boron, René Zavaleta and Ruy Mauro Marini.

Key wORDS: Agustín Cueva; Dictatorships; Latin America; Fascism.

Recibido: 19 de febrero de 2018

Aceptado: 27de junio de 2018

Universidad de Buenos Aires, conICET (andrestzeiman@hotmail.com). 


\section{INTRODUCCIÓN}

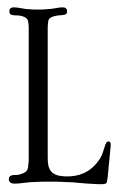

os años sesenta, tras el impulso de la Revolución Cubana, fueron protagonistas de una agudización creciente de la lucha entre clases en las diversas partes de América Latina, ya sea por medio de movimientos políticos nacional-populares o de carácter socialista. Ese clima de radicalización se extendió durante los primeros años de la década de los setenta, en los que despuntó como máxima expresión en la región el proceso chileno de la Unidad Popular. Pero el golpe militar ocurrido en ese país en 1973 daría inicio a una ola de dictaduras, que se expandiría hacia otras naciones latinoamericanas, completando el panorama previo que ya presentaba gobiernos de facto en países como Paraguay o Brasil. De esa manera, al final de los setenta el cono sur latinoamericano estaba invadido por dictaduras militares cuya instauración venía a colocar un freno al mencionado avance popular.

En ese marco, en un artículo titulado "América Latina en el último quinquenio: 1976-1980", publicado en 1980 en la revista Araucaria (cuyo director, desde el exilio, era el dirigente comunista chileno Volodia Teitelboim), el sociólogo ecuatoriano Agustín Cueva retrataba de la siguiente forma el paisaje político que reinaba en la región en los últimos años de la década de los setenta:

Un breve recuento de la situación de América Latina al comenzar la segunda mitad de la década pasada [la de los setenta] sirve para recordarnos el panorama harto deprimente que caracterizaba a la región en aquel entonces. La dictadura militar del país más importante del subcontinente, el Brasil, parecía estar plenamente consolidada al cabo de doce años de ejercicio del poder y dotada de una gran capacidad de expansión en todos los órdenes. En Bolivia, país tradicionalmente turbulento, la dictadura de Banzer tenía vizos de haber impuesto < por fin > un orden estable proimperialista. Uruguay y Chile sufrían, por su parte, los más rigurosos efectos de los regímenes fascistas instaurados desde 1973; mientras en la Argentina el gobierno de la señora Estela Martínez de Perón se desmoronaba, dando paso a la férrea dictadura del general Videla. Sojuzgado por la tiranía de Stroessner desde 1954, el Paraguay no hacía más que corroborar el trágico cuadro del Cono Sur de América Latina (Cueva 1980: 7). 
No hacen falta mayores precisiones para afirmar que el contexto latinoamericano resultaba, en ese entonces, bastante sombrío. Sin embargo, en materia teórica, dicha situación concitó un profundo interés en la intelectualidad crítica de la región, ligado tanto a la necesidad de explicar el fenómeno de las dictaduras emergentes como a reflexionar sobre la estrategia que debían adoptar los movimientos populares en los diferentes países, con el objeto de acabar con los regímenes de facto y reinstaurar condiciones favorables de lucha de cara a la transformación del orden social. Por esa razón, la bisagra de los setenta y ochenta no resultó residual en términos de producción teórica. Por el contrario, aquellos años fueron en nuestras ciencias sociales sumamente prolíficos en varios aspectos.

En las páginas que siguen nos interesa recuperar un campo de discusión y aporte teórico que fue central en la bisagra de los años setenta y ochenta y que, creemos, nos ha legado valiosas contribuciones en materia de teoría política. Aportes que, según nuestro punto de vista, resultan aún de mayor interés en el contexto de una actualidad de América Latina donde parece renacer con fuerza la derechización y el autoritarismo político (fundamentalmente en el cono sur, con eje en Brasil y Argentina).

Ensayaremos aquí la recuperación de aquellos debates sobre las dictaduras militares de fines de los setenta y comienzos de los ochenta en América Latina, desde una óptica particular. Lo haremos a partir de las huellas dejadas en ese campo por la trayectoria de un intelectual que consideramos un pilar de la sociología crítica latinoamericana, quien además fuera un destacado animador - polémico y provocador por naturalezade acaloradas discusiones teóricas en la academia de nuestra región. Nos referimos al sociólogo ecuatoriano Agustín Cueva. ${ }^{1}$

1 Sintetizamos a continuación una breve biografía intelectual de Agustín Cueva. Entre 1967 y 1970 trabajó en la Universidad Central de Quito, donde fue profesor y director de la Escuela de Sociología, profesor de Economía y responsable de la revista Hora Universitaria. Luego se dirigió a Chile, donde fue profesor de teoría literaria en la Universidad de Concepción entre 1970 y 1972. De forma posterior, emigró hacia México, país en el que desarrollaría la mayor parte de su vida intelectual. Allí, fue catedrático de la Facultad de Ciencias Políticas y Sociales de la Universidad Nacional Autónoma de México (UNAM) e investigador del Centro de Estudios Latinoamericanos (CELA) entre 1972 y 1992. Entre 1980 y 1986, también fue profesor de la División de 
El campo de discusión que abordaremos en este artículo será la caracterización de las dictaduras que se afirman en América Latina a mediados de los años setenta. Una polémica que estuvo marcada fundamentalmente por el debate sobre la pertinencia de la categoría de fascismo (acompañada, según el autor que la empleara, por distintos adjetivos como "dependiente", "primario", "del subdesarrollo", entre otros) en tanto vehículo explicativo de la etapa política por la que estaban atravesando los países de la región.

Antes de comenzar a desarrollar este trabajo, creemos importante señalar que la figura de Cueva y sus aportes teóricos a propósito del autoritarismo y las dictaduras militares en América Latina no constituyeron contribuciones aisladas en nuestras ciencias sociales durante los años setenta y ochenta. Estuvieron más bien inscritas en un campo de discusiones que aglutinó a buena parte de la intelectualidad crítica, residente en aquel entonces fundamentalmente en la academia mexicana. Por eso, trataremos de reconstruir esos debates, ponderando especialmente la participación de Cueva en ellos, pero estableciendo a su vez un diálogo con otros cientistas sociales que también intervinieron con ímpetu en aquellas controversias.

DISCUSIONES TEÓRICO-POLÍTICAS A PROPÓSITO DEL AUTORITARISMO, LAS DICTADURAS MILITARES EN AMÉRICA LATINA Y EL CONCEPTO DE FASCISMO

La polémica acerca de la caracterización de las dictaduras militares emergentes y ya establecidas en la región para la segunda mitad de los años setenta tuvo un papel protagónico en el debate de la intelectualidad crítica latinoamericana. En ese marco, Cueva dedicó varios artículos al abordaje de esta cuestión, los cuales fueron publicados en distintas revistas o li-

Estudios de Posgrado en la Facultad de Economía de la UNAM. Entre sus libros más destacados se pueden mencionar Entre la ira y la esperanza (1967), El desarrollo del capitalismo en América Latina (1977) y Teoría social y procesos políticos en América Latina (1979). 
bros, aunque luego serían compendiados de forma conjunta en la segunda parte del volumen de su autoría Teoría social y procesos políticos en América Latina. Si bien pueden desprenderse de esos escritos diferentes facetas de análisis del fenómeno dictatorial (como el contexto político, las especificidades nacionales, la política económica, etc.), consideramos que dos de esos trabajos resultan de especial interés. Por un lado, nos referimos a aquel que fuera publicado inicialmente en la Revista Mexicana de Sociología en 1977, en forma contigua a un artículo del politólogo argentino Atilio Boron (abocado al mismo problema y destinado precisamente a polemizar con Cueva y otros intelectuales que acuñaron el concepto de fascismo). Por la otra parte, aludimos a la exposición en una mesa redonda de un seminario realizado en la unAm, y convocado bajo el título "Las fuentes externas del fascismo", que compartiera con Theotonio dos Santos y Ruy Mauro Marini, y que luego fuera publicada en la revista Cuadernos Políticos.

El primero de esos dos trabajos posee mayor densidad teórica. Allí, el sociólogo ecuatoriano no sólo establece una definición del fascismo, sino que también explica los motivos por los cuales tal categoría, desde su perspectiva, resulta apropiada para caracterizar a los regímenes políticos por entonces emergentes en América Latina. Es decir, se concentra en brindar precisiones conceptuales acerca del nivel de abstracción que supone la utilización de la categoría de fascismo y, en función de ello, explica su pertinencia para la comprensión de la realidad latinoamericana de aquellos días.

En ese sentido, para introducir la pertinencia de la categoría de fascismo intenta distinguir las implicaciones de la adopción del marxismo como matriz analítica, en relación con las consecuencias que supondría la adscripción al corpus weberiano. Según Cueva, esa elección teórica significa desechar la construcción de un "tipo ideal", útil para evaluar situaciones que pueden presentar rasgos afines. Alternativamente, a partir de un punto de vista marxista, sostiene:

En cambio, si uno se coloca en una perspectiva de análisis marxista la cuestión se plantea en términos radicalmente distintos. Ya no se trata de cons- 
truir modelos "culturalmente" significativos ni de trabajar con categorías puramente descriptivas, sino de empezar operando una distinción neta entre lo que es objetivamente esencial y aquello que no lo es, de acuerdo con la teoría materialista y dialéctica y mediante la aplicación de sus categorías más adecuadas a la naturaleza del fenómeno que se busca analizar. Lo que interesa en el caso de regímenes como los del Cono Sur de América Latina es, pues, conocer su esencia, y no por mero capricho intelectual sino porque ese conocimiento es de vital importancia para la acción política (Cueva 1979a: 165).

De esa manera, el sociólogo ecuatoriano se ocupa de precisar aquello que, según él, es objetivamente esencial en el concepto de fascismo. Es decir, se concentra en marcar las características definitorias de ese fenómeno. Así, desde su punto de vista, los elementos esenciales del fascismo son los siguientes: 1) ser una dictadura en la que el sector monopólico de la burguesía tiene el predominio; 2) adquirir un carácter terrorista produciendo un cambio cualitativo en la forma de dominación y en la forma de Estado, al operar una ruptura radical con las formas democrático-burguesas; 3) ser ejercido en lo fundamental contra la clase obrera; y 4) aparecer, de acuerdo con lo señalado oportunamente por el dirigente comunista italiano Palmiro Togliatti, como "el remedio infalible en donde el capitalismo atraviesa por una crisis y teme un colapso". Elementos cuya estructura básica radica en un rabioso anticomunismo (Cueva 1979a: 165-166).

Por supuesto, esto no significa que Cueva considere a las distintas dictaduras latinoamericanas emergentes en la segunda mitad de los setenta como "repeticiones" de los fascismos europeos (principalmente de los casos de Italia y Alemania). Tampoco implica que las entienda a todas ellas como iguales entre sí. Para clarificar su posición, vale la pena citar de manera extendida sus propias palabras al respecto:

Dentro de la unidad que constituye el fascismo hay obviamente margen para la diversidad, y ello por una razón más que no cabe olvidar: el desarrollo dialéctico de la historia, determinado por la lucha de clases, hace que nunca se den superestructuras "químicamente" puras, cristalizadas de una vez por todas. Se trata siempre de procesos en que diversos elementos se combinan de manera compleja, produciendo ciertamente rupturas de orden 
cualitativo sin las cuales sería imposible hablar siquiera de distintas formas de Estado, pero abriendo al mismo tiempo un abanico de gradaciones y matices [...] Entre el plano de lo esencial-universal y el de las singularidades concretas existe además un plano intermedio, el de la particularidad, que el análisis materialista no puede pasar por alto. En el caso de América Latina, esta particularidad está dada por el hecho de tratarse de países subdesarrollados y dependientes, con una economía atrasada, deformada y que ocupa una posición siempre subalterna en el seno de la constelación capitalista-imperialista mundial (Cueva 1979a: 171; énfasis del original).

Es decir, el fascismo resulta, según Cueva, un concepto con validez universal a partir de determinadas características que lo definen como tal, pero a su vez permite comprender bajo su órbita diversas realidades que son fruto de la imaginación histórica, más aún por tratarse de un fenómeno del orden de las superestructuras.

Pues bien, con base en esta caracterización se pueden desprender al menos dos líneas de debate con otras posiciones teóricas. La primera de ellas se halla vinculada al grado de relevancia del régimen político en la definición del contexto latinoamericano, y en función de ello, la pertinencia de la categoría de fascismo para conceptualizar lo que estaba ocurriendo en ese entonces en América Latina. La segunda está relacionada con el nivel de abstracción del concepto de fascismo. Es decir, en qué medida tal categoría, nacida en Europa en la tercera década del siglo xx, podía ser utilizada para describir una situación histórica como la de nuestra región en la tercera parte de ese mismo siglo, en formaciones económico-sociales disímiles e insertas de un modo diferente en el sistema mundial.

La primera de esas dos líneas de discusión - sobre el grado de relevancia del régimen político- se desarrolla en contrapunto con el intelectual brasileño Ruy Mauro Marini, en el marco de la mencionada mesa redonda llevada a cabo en la UNAM en 1978. Allí, Marini sostiene que las dictaduras son el fruto de un proceso latinoamericano que tiene tres vertientes: el cambio de estrategia global norteamericana, con la consecuencia en el plano militar de la formulación de una doctrina de contrainsurgencia; la transformación estructural de las burguesías criollas, en las que se desarrolla una burguesía monopólica vinculada estrechamente al 
imperialismo; y el ascenso del movimiento de masas, al que la burguesía debe enfrentar con ímpetu. Ahora, desde su perspectiva, las dictaduras militares son la expresión formal del Estado, mas no la esencia del mismo. Así, Marini afirma que en América Latina nos encontramos en presencia de Estados de contrainsurgencia cuya característica principal es la conducción conjunta de la dirección estatal por parte de las Fuerzas Armadas y el capital monopólico, más allá de su expresión formal y coyuntural como dictaduras.

El Estado de contrainsurgencia, consecuencia de una reacción contrarrevolucionaria de la burguesía en la región, se define por la distinción entre dos ramas de decisión emergentes en la esfera estatal. La hipertrofia ejecutiva del Estado se presenta a través de una rama militar (Estado Mayor Conjunto de las Fuerzas Armadas y órganos del servicio de Inteligencia) y una rama económica (ministerios económicos, empresas estatales de crédito, producción y servicios). Ambas ramas confluyen en el Consejo de Seguridad Nacional, órgano cúspide de este experimento estatal. De ese modo, el Estado de contrainsurgencia consagra la alianza entre las Fuerzas Armadas y el capital monopólico, y se constituye en un poder al margen de las instituciones básicas del clásico Estado burgués, como son las legislativas y judiciales. Sin embargo, este Estado no necesariamente tiene que ser una dictadura, puede también configurar, según Marini, un régimen civil (como en aquel entonces en Venezuela).

Según nuestro modo de ver, en las siguientes palabras del autor de Dialéctica de la dependencia se encuentra explicada su visión acerca del papel que desempeña el régimen político en la definición de la etapa latinoamericana:

En síntesis, el Estado de contrainsurgencia es el Estado corporativo de la burguesía monopólica y las Fuerzas Armadas, independientemente de la forma que asuma ese Estado, es decir, independientemente del régimen político vigente. Dicho Estado presenta similitudes formales con el Estado fascista, así como con otros tipos de Estado capitalista, pero su especificidad está en su peculiar esencia corporativa y en la estructura y funcionamiento que de allí se generan. Llamarlo fascista no nos hace avanzar un paso en la comprensión de su significado (Marini 1978; énfasis del original). 
Creemos importante señalar dos cuestiones vinculadas con estas definiciones de Marini. Por una parte, si bien realiza algunas observaciones, no se dedica a establecer con precisión una definición de fascismo, de modo tal de cuestionar con rigurosidad las posiciones que identificaban a las dictaduras latinoamericanas con esa forma de Estado. Tan sólo señala que mientras los fascismos no defendieron la democracia burguesa, los gobiernos de facto de nuestra región erigieron su excepcionalidad precisamente en defensa de ella. Si tomamos en consideración que la mesa redonda fue titulada precisamente "Las fuentes externas del fascismo", y que tal era el tópico central del debate teórico, el desarrollo de mayores detalles sobre la categoría de fascismo hubiese resultado útil para clarificar su posicionamiento.

En segundo lugar, vimos más arriba que Cueva destaca, entre los rasgos esenciales del fascismo, la ruptura radical con las formas democrático-burguesas. Hay allí una valoración sustantiva del significado que supone un quiebre en el régimen político y la forma estatal. No sucede lo mismo con Marini. La conceptualización de un Estado de contrainsurgencia no halla su fundamento en lo que el intelectual brasileño llama "la expresión formal del Estado". Más bien reclama, como observamos en la cita más arriba, la independencia de aquel Estado con respecto al régimen político. Según nuestra mirada, esa desestimación del aspecto formal del Estado, o bien del régimen político, constituye un severo error analítico, pues no coloca la atención merecida sobre el papel que desempeña en determinados contextos la dimensión coercitiva del Estado en el ejercicio de la dominación capitalista, y en particular, en el marco de momentos de excepcionalidad en el mapa de correlaciones de fuerzas. Ello no significa quitar relevancia al carácter común que pueda tener en toda la región la intervención norteamericana, la fase de acumulación de capital o el sector hegemónico de la burguesía (aunque hayan existido en ese sentido notorias diferencias entre los países). Implica más bien otorgar a la forma estatal el lugar que le corresponde en el análisis, pues de lo contrario, la falta de atención y rigurosidad conceptual en ese punto puede tener sensibles consecuencias en materia de estrategia y acción política. Creemos 
contundentes en ese sentido las reflexiones de René Zavaleta en un texto del que nos ocuparemos en profundidad más adelante:

Ahora bien, se nos ocurre que prestar poca atención a la diferencia que se da entre el Estado como esencia y el Estado como práctica o aparición es ya un grave error, es cierto que cada vez menos frecuente. Pero lo es aún más, acarreando consecuencias nefastas, el no distinguir (esto tiene una importancia ya estructural) entre una manera y otra que adquiera la práctica estatal; para decirlo en otros términos, el grado de democracia con que se ejerza la dictadura. Los oprimidos que no aprenden a discriminar entre un momento u otro de la clase dominante, tampoco tienen los elementos para distinguir sus propios momentos (Zavaleta 1990: 11).

Desplazándonos ya hacia la segunda línea de debate, como señalamos más arriba, ella estuvo relacionada con el nivel de abstracción e historicidad del concepto de fascismo. Si bien el trabajo más elaborado teóricamente al respecto es sin duda el ya mencionado de Atilio Boron que fuera publicado en la Revista Mexicana de Sociología, ${ }^{2}$ también el boliviano René Zavaleta escribió interesantes aportes a propósito del tema.

Como mencionamos más arriba, el punto central que distancia a Boron de la conceptualización del fascismo realizada por Cueva es la concepción que aquél tiene de tal categoría como expresión histórica, en contraposición con la utilización que hiciera el ecuatoriano como concepto abstracto-formal. Así, Boron sostiene el carácter histórico del fascismo como una forma del Estado capitalista de excepción (diferente de otras, como el bonapartismo o las dictaduras militares). Desde su punto de vista, según la perspectiva dialéctica el fascismo constituye una forma específica de contrarrevolución burguesa. Mas no cualquier forma de reacción de las clases dominantes, sino una modalidad muy particular de ella. Por lo tanto, la preocupación principal del politólogo argentino es cuestionar críti-

2 Si bien dicho artículo, titulado "El fascismo como categoría histórica: en torno al problema de las dictaduras en América Latina", fuera publicado originalmente en esa revista mexicana (en el número 2 de abril-junio, 1977), aquí utilizaremos la versión del mismo trabajo que forma parte del libro Estado, capitalismo y democracia en América Latina, que compila diferentes artículos de Boron. 
camente a quienes acuden al concepto de fascismo al observar regímenes plenos de represión y terror, diluyendo en esa dimensión coercitiva tal categoría, e ignorando de esa manera las determinaciones que supone analizar sociedades capitalistas como las latinoamericanas, dotadas de características particulares (Boron 2003: 43-48).

En ese sentido, el texto de Boron despliega un análisis sistemático, ordenando argumentalmente su exposición a través de tres pasos sucesivos. El primero: definición del fascismo como categoría histórica. Segundo: descripción de la nueva modalidad de acumulación de capital en el contexto latinoamericano en el que emerge el fenómeno de las nuevas dictaduras militares. Tercero: caracterización de los nuevos regímenes políticos dictatoriales en América Latina.

De ese modo, presenta las siguientes definiciones del fascismo como categoría histórica: 1) se sitúa históricamente en el periodo de maduración y crisis de la fase clásica del imperialismo; 2) existía ya en su contexto histórico un notable desarrollo del capitalismo de resultas del cual la burguesía monopólica nacional emergió como la fracción predominante de la economía, no así con la primacía en la superestructura política. El fascismo fue, entonces, un reacomodo de fuerzas sociales; 3) el modelo de acumulación capitalista requería necesariamente la búsqueda y el control de los mercados exteriores; 4) el Estado fascista se edificó sobre los escombros de una frustrada ofensiva revolucionaria de la clase obrera y sobre los hombros de una masiva movilización de la pequeña burguesía; 5) la ideología fascista, a pesar de su carácter de "amalgama contradictoria”, representó un intento de sustitución de la vieja ideología liberal, y 6) una reestructuración del aparato estatal y las relaciones entre las clases (Boron 2003: 59-61).

A la hora de establecer una comparación entre dichas definiciones sobre el fascismo y la situación latinoamericana, Boron afirma que el punto de partida para ello es observar con detenimiento los cambios operados en el escenario internacional. Es decir, comprender la modalidad específica bajo la cual comienza a desarrollarse la acumulación capitalista tras la crisis ocurrida en los años sesenta. Para ello, destaca las siguien- 
tes características de esa nueva modalidad de acumulación: a) masivas inversiones en las ramas más dinámicas del sector industrial; b) elevadas tasas de ganancia del sector "concentrador y dinámico" de la economía, mantenidas a través de una serie de mecanismos (por ejemplo: reducción de salarios reales y anulación de derechos laborales) que contrarrestaron los efectos negativos derivados de la elevada composición orgánica del capital; c) recorte de los ingresos de los asalariados en favor de la burguesía; d) orientación de la producción local más sofisticada a los mercados externos, y e) redefinición de las funciones económicas del Estado hacia la creación de condiciones favorables para la atracción de empresas transnacionales (Boron 2003: 65-67).

Por lo tanto, señala Boron, la reorganización económica y social que reclamaba el despliegue de la nueva modalidad de acumulación no podía ser llevada a cabo en las condiciones propias del sistema democrático-burgués. Pues, tal como sostiene Manuel Antonio Garretón, esa transformación demandaba cancelar con autoridad los "excesos" o "exageraciones" en materia de intervencionismo estatal y de redistribución progresiva del ingreso, propios del "Estado de compromiso" entonces en crisis (Garretón 1982: 9-10). La reestructuración económica requería cancelar, al menos temporalmente, las libertades democráticas, de modo tal que las clases dominantes pudieran implementar con menor dificultad las medidas que les resultaban necesarias. Todo ello, aunque su costo fuera la aplicación de la represión y el terror que caracterizara a los regímenes políticos instaurados en los años setenta en América Latina.

Considerando el nuevo escenario internacional y la modalidad específica de acumulación capitalista en la periferia, el politólogo argentino se encarga de repasar las características de los nuevos regímenes políticos dictatoriales en América Latina, y con ellas, sus diferencias en relación con las experiencias históricas del fascismo: 1) se sitúan en una fase de la evolución del capitalismo monopólico, signada por la emergencia de un gran conglomerado transnacional, concentrado e internacionalizado; 2) ascenso a la posición hegemónica por parte de la burguesía monopólica transnacional; 3) ausencia de una base de masas que sirva de apoyo (más allá del 
respaldo de ciertos sectores de la población); 4) no elaboraron una ideología totalitaria, que apele a las justificaciones ideológicas del nacionalismo, la autarquía y la soberanía; 5) surgimiento de la Fuerzas Armadas como el partido orgánico de la gran burguesía monopólica (Boron 2003: 69-80).

Para finalizar, Boron denomina a estos regímenes como un Estado militar. Y explica esa conceptualización de la siguiente manera:

... lo que deseamos enfatizar aquí es que el "Estado militar" es la alternativa histórica al fascismo, la "solución actual" que genera la nueva fase del desarrollo capitalista en la periferia. Refleja otro tipo de crisis económica, política e ideológica para otra alianza de clases dominantes en una nueva modalidad de acumulación. Existe, claro está, un "aire de familia" entre el fascismo y estos regímenes dado que ambos son formas reaccionarias de excepción del Estado capitalista y expresan la contrarrevolución burguesa que pretende resolver una crisis orgánica en distintos momentos. Pero ahí se acaba su semejanza (Boron 2003: 83; énfasis en el original).

En síntesis, considera que la represión y el terror como características de un Estado de excepción capitalista no resultan elementos suficientes para definir el fascismo, pues este último estuvo constituido por ciertos rasgos históricos, que en la nueva modalidad de acumulación de capital y en el marco de sociedades periféricas y dependientes no pueden ser replicados utilizando un criterio abstracto-formal. Así, el concepto de Estado militar, según Boron, permite visualizar con mayor claridad las características de los nuevos regímenes políticos en América Latina.

Por su parte, también René Zavaleta realizó interesantes contribuciones en esta polémica. Desde nuestro punto de vista, sus aportes resultan complementarios a los llevados a cabo por Boron, pues ciertamente, el intelectual boliviano no trabaja teóricamente y de manera específica sobre la historicidad de la categoría de fascismo. A su vez, sus ideas están expresadas en artículos de menor extensión y planteadas con mucha menor sistematicidad que las del politólogo argentino. Sin embargo, consideramos que sus trabajos desarrollan una arista de análisis del fenómeno fascista a la que Boron no dedica plena atención; nos referimos al abordaje del 
vínculo entre fascismo y cuestión nacional, como un punto de divergencia entre los regímenes de excepción en Europa y en América Latina. Un aspecto que se relaciona íntimamente con la centralidad que Zavaleta otorgara a la cuestión nacional en el conjunto de su obra.

Entonces, para abordar los aportes de Zavaleta podemos concentrarnos en dos textos de su autoría: El fascismo y la América Latina (1976) y Notas sobre fascismo, dictadura y coyuntura de disolución ([1978]). En ambos el pensador boliviano establece como eje vertebral del análisis la continuidad (o discontinuidad) entre formación del Estado Nacional e instauración de la democracia burguesa, y entiende a este último como aquel régimen político que permite el "mejor" desenvolvimiento del desarrollo capitalista. Precisamente, además de la primacía del capital monopólico, es ese vínculo entre nación y democracia burguesa el que estructura su definición del fascismo. Como explica el propio Zavaleta en sus Notas sobre fascismo:

Fue Hilferding el que definió al fascismo como "el intento de organizar en forma totalitaria el conjunto de la vida social de acuerdo a los intereses del capital monopólico". Pero es además un fruto característico de los países que han llegado tarde a la conformación de los datos de base de un proceso capitalista y que, como consecuencia de tal rezagamiento, no se instalan con solidez y soltura en lo que se puede llamar la normalidad del Estado capitalista, que es la democracia burguesa. Lo decisivo, a nuestro modo de ver, está en la proximidad que hay entre la resolución tardía de la cuestión nacional y la precoz aparición del capital financiero, hecho que tiene también su causa en lo anterior (Zavaleta 1990: 3).

Vemos cómo la construcción tardía de la nación constituye, según el autor boliviano, un punto de apoyo fundamental para el desencadenamiento de procesos fascistas. Porque la forma no democrático-burguesa de conformación nacional permite la emergencia de movimientos de masas consustanciados con el cumplimiento, precisamente, de las tareas nacionales. Tal es el motivo por el cual Zavaleta sostiene que el fascismo está ligado, al mismo tiempo, a las necesidades del capital monopólico (tal como afirmara Hilferding) y a la deriva ideológica que asuma la pequeña 
burguesía ante un contexto de crisis general. Ésta, ante la falta de viabilidad de un proyecto estatal de las clases subalternas, tiende a reaccionar en esos contextos de acuerdo con sus reflejos esenciales como clase (es decir, identificándose con la burguesía). Por ende, según Zavaleta, los fascismos se caracterizan por irrumpir en momentos de crisis en aquellos países de Europa donde la construcción de la nación no se ha producido de un modo revolucionario, democrático-burgués, sino de forma tardía y "desde arriba". Allí, entonces, las tareas nacionales inconclusas son retomadas por movimientos de masas que pretenden saldar esa deuda histórica. Mas lo hacen en contextos críticos, y en los que el desarrollo del capital monopólico se encuentra en condiciones de sepultar el capitalismo de libre concurrencia y su ideología liberal.

Pues bien, Zavaleta comprende el fascismo como una forma de Estado que es consecuencia de condiciones coyunturales y anómalas del capitalismo. Porque como sucede con cualquier forma dictatorial, estas últimas no constituyen la manera más favorable de desarrollo de ese modo de producción. Ahora bien, en el momento de analizar la pertinencia del concepto de fascismo para categorizar las nuevas dictaduras en América Latina, el boliviano sostiene que no alcanza con la adopción de modalidades fascistoides en cuanto a la desorganización del movimiento popular y el tipo de organización del Estado para afirmar que se ha instalado el fascismo. Más bien considera que la utilización de dicha categoría para nuestra región puede generar algunas dificultades (Zavaleta 1988: 207).

En ese sentido, Zavaleta se instala en la especificidad de los procesos dictatoriales latinoamericanos, al establecer como elemento primordial del análisis el hecho de que nuestra región ha estado históricamente sometida a la dominación del imperialismo norteamericano. Esa presencia imperial ha resultado una causa central para la inconclusión de las tareas nacionales, y más aún, para el carácter excluyente que asumieron nuestras naciones. Por lo tanto, el cumplimiento de esas tareas difícilmente hubiera podido estar asociado con los intereses norteamericanos y los capitales monopólicos. Así, Zavaleta plantea una distinción entre el fascismo como proyecto, como movimiento de masas y como estructura de poder. Tres rasgos 
que, más allá de la posibilidad de existencia de un proyecto fascista, no se han dado de forma conjunta en tierras latinoamericanas. Para brindar mayor claridad al respecto, creemos útil citar in extenso las palabras del autor de Lo nacional-popular en Bolivia:

Lo fundamental a nuestro modo de ver, si ahora retomamos la cuestión del fascismo es distinguir entre el fascismo como proyecto o proposición social, del fascismo como movimiento de masas y el fascismo como estructura de poder [...] en el caso de las dictaduras latinoamericanas actuales se configura una situación en la que el proyecto de quienes detentan el aparato del Estado no se funda en un movimiento de masas y, por consiguiente, no compone una estructura fascista de poder. Esto tiene su origen a nuestro modo de ver en la proposición extrínseca que tiene ese proyecto [...] Es verdad sin duda que la cuestión nacional no está concluida en los países de América Latina. Pero no lo está precisamente por la presencia imperialista. Por lo tanto, las masas no pueden plantear el tema en la política sino bajo la forma de movimientos de liberación nacional. En esas condiciones, el enlazamiento entre capital monopólico y la cuestión nacional no puede producirse y ésta es la razón por la cual ninguno de los proyectos fascistas emitidos desde el poder ha podido manifestarse como movimiento de masas, y por consiguiente, tampoco como estructura de poder. Han sido proyectos que no han obtenido legitimación ideológica al nivel de las masas (Zavaleta 1990: 15-16).

La imposibilidad de construcción de un movimiento de masas resulta fundamental en la conceptualización de Zavaleta, pues tal movimiento no puede erigirse en función de un proyecto que a todas luces se muestra excluyente y subordinado a intereses extrínsecos, pero principalmente, contrarios a los de las mayorías en el plano de la nación. Esa es la principal diferencia entre los casos de Europa y América Latina: mientras los primeros tenían una vocación imperial-anexionista, que permitía la ligazón con el capital monopólico, los segundos se caracterizaron por la dependencia y la sujeción a los intereses del imperialismo norteamericano. En su artículo "El fascismo y la América Latina", el intelectual boliviano es contundente al respecto: 
Por otra parte, en lo que resulta un hecho central para explicar las imposibilidades tanto de este esquema como de sus símiles continentales, es menester darse cuenta de que aquí el fascismo no nace como un proyecto nacional. Es un golpe de Estado dado por una minoría racista, antipopular y bajo el apoyo y la convocatoria masiva del imperialismo norteamericano. Cualquiera que sepa algo de fascismo asumirá que el origen extranacional del proyecto es algo que atenta contra sus propias posibilidades de integración orgánica (Zavaleta 1988: 209).

En resumidas cuentas, creemos que Zavaleta introduce el problema nacional como el eje vertebral del análisis de la cuestión del fascismo en América Latina, ensanchando la mirada en relación con el nuevo escenario internacional y la transformación en la modalidad de acumulación capitalista que da origen a estos regímenes de excepción. Por eso, desde nuestro punto de vista, el abordaje de la dimensión nacional brinda un enriquecimiento a los aportes esclarecedores que realizara Boron acerca de la caracterización de las dictaduras latinoamericanas de los años setenta.

Pues bien, toca ahora exponer nuestra mirada acerca de los aportes de Agustín Cueva en esta polémica. Con respecto a la línea de debate establecida con Marini, entendemos que la posición del ecuatoriano resulta apropiada y rigurosa. Más allá del carácter determinante de la modalidad de acumulación de capital y del papel represivo de las Fuerzas Armadas en el nuevo contexto, la ruptura del orden democrático-burgués no puede constituir un dato accesorio. El régimen político es un aspecto sustantivo que repercute notablemente en la lucha política, pues establece las condiciones en las cuales las clases subalternas disputan el poder. En ese sentido, Marx, en diversos trabajos, fue contundente a la hora de señalar que la apariencia de las cosas juega un papel crucial en el desenvolvimiento de la sociedad burguesa. Ciertamente el papel del proletariado y sus organizaciones es precisamente develar la esencia de la dominación que se esconde detrás de las expresiones formales, mas ello no significa que las formas resulten secundarias, pues en definitiva esa es una operación característica de la sociedad capitalista: la existencia de movimientos aparentes. Tal como sostiene el politólogo argentino Guillermo O’Donnell (1977) en sus Apuntes para una teoría del Estado, cuando el Estado capitalista funciona 
por medio del uso directo de la violencia, queda al descubierto su carácter coconstitutivo en el ejercicio de la dominación y desnuda asimismo su condición de clase, invalidando de ese modo su presunta imparcialidad. Por lo tanto, el régimen político no puede resultar un elemento independiente sino que ocupa un lugar trascendental en la conceptualización del poder del Estado, más allá de la utilización de la categoría de fascismo. Por eso, creemos que en ese punto el sociólogo ecuatoriano caracterizó a las dictaduras latinoamericanas de una manera adecuada.

Pero la discusión más enriquecedora consideramos que fue la entablada con Atilio Boron. Allí, desde nuestro punto de vista, fue el argentino quien se aproximó al fenómeno de un modo más atinado. No obstante, pensamos que aquí se hace presente en Cueva una tensión característica de su obra entre la tendencia a utilizar categorías universales y la realidad latinoamericana (Tzeiman 2016), pues resulta curioso en este sentido que el ecuatoriano reconoce en sus textos muchos de los aspectos a los que Boron hace alusión; sin embargo, termina primando su insistencia en acuñar categorías con pretensiones de universalidad (en este caso la de fascismo), antes que la especificidad latinoamericana. Decimos que esto resulta curioso ya que, como señalábamos más arriba, Cueva no desconoce la diversidad de formas en que los regímenes de excepción pueden expresarse. Tampoco desestima el modo en que ellos se realizan en América Latina. Así, en su intervención en la mesa redonda llevada a cabo en la UNAM, sostiene:

el concepto de fascismo no cierra en modo alguno, las posibilidades de análisis de cada situación nacional, con todas las determinaciones y peculiaridades específicas que pueden presentar. Al menos en la perspectiva marxista la categoría de fascismo es una categoría abierta a la historicidad (Cueva 1979b: 177).

Lo mismo podemos decir acerca de algunas ideas que repasáramos de Zavaleta. En ese sentido, Cueva presta atención a las características que asumen las dictaduras en vista de la condición dependiente y subdesarrollada de América Latina. Asimismo, observa como un factor determinante la presencia del imperialismo en la región. Tal es así que, al igual que el 
autor boliviano, se encarga de señalar la imposibilidad de los regímenes latinoamericanos de presentar una faz nacionalista, en la medida en que existen férreos nexos que ligan a las dictaduras con la burguesía imperialista. Por eso, afirma Cueva, en nuestras naciones dependientes, el Estado y sus fuerzas represivas cumplen la función de un ejército imperialista de ocupación, en "guerra interna" contra el conjunto del pueblo (Cueva 1979c: 147-149).

En definitiva, al evaluar la utilización del concepto de fascismo, creemos que Cueva incurre en el mismo equívoco que Antonio Gramsci, en sus "Notas sobre el ensayo de sociología popular de Bujarin" pertenecientes a sus célebres Cuadernos de la cárcel, denominara idealismo especulativo. Una operación que significaba para Gramsci desarrollar una teorización con base en clasificaciones y conceptos empíricos, luego aplicados a otros contextos sociohistóricos, produciendo de esa forma un "idealismo al revés" por medio del cual tales clasificaciones terminan resultando "tan abstractas y antihistóricas” como las categorías especulativas (Gramsci 2003: 142).

De cualquier modo, como consecuencia del conocimiento riguroso que Cueva posee sobre la realidad latinoamericana, dicha operación no deriva en una lectura histórica y política mistificada e imprecisa del fenómeno que busca analizar. Por ese motivo, aun cuando consideramos que en esta polémica los aportes de Boron y Zavaleta resultaron teóricamente más precisos que los de su par ecuatoriano, creemos que los diversos artículos escritos por este último acerca de los regímenes dictatoriales instaurados en América Latina en la segunda mitad de los años setenta presentan elementos esclarecedores para la conceptualización e intelección de ese fenómeno político que en aquel entonces experimentara la región.

\section{PALABRAS FINALES}

Como conclusión de este trabajo podemos empezar haciendo una breve síntesis de las distintas posiciones que buscaron caracterizar las dictaduras de mediados de los años setenta en América Latina, ya reseñadas en este artículo. 
En primer lugar, podemos señalar que se han enfrentado dos posturas acerca de la fecundidad del concepto de fascismo para pensar las dictaduras latinoamericanas de mitad de los años setenta. Una de ellas, la de Cueva, enfatizaba el carácter universal de la categoría y su utilidad para inteligir los gobiernos de facto entonces en boga en la región. Mientras que la otra posición, sistemática en Boron y más dispersa en Zavaleta, sostenía que la etapa particular del desarrollo capitalista a escala mundial, así como el papel dependiente que en ella desempeñaba nuestra región, volvían infructuosa la categoría de fascismo para comprender los regímenes autoritarios de mitad de los años setenta.

A su vez, existieron distintas apreciaciones acerca de la relevancia del problema de los regímenes políticos al analizar los gobiernos dictatoriales. Marini, en su conceptualización de los Estados de contrainsurgencia, consideraba dicha cuestión un aspecto secundario, pues aquello verdaderamente importante residía en la alianza entre las Fuerzas Armadas y el capital monopólico, en tanto ambos se erigían como poderes fácticos del Estado. Por el contrario, en sus diferentes lecturas, Cueva, Zavaleta y Boron, ponderaron especialmente el carácter del régimen político, en tanto éste suponía condiciones particulares de lucha para las clases subordinadas que entonces resistían los embates de los autoritarismos militares.

Por otro lado, Zavaleta se distinguió en sus intervenciones por insertar en sus análisis de las dictaduras de los años setenta aquel dilema teórico-político que atravesó de conjunto a la totalidad de su obra: la cuestión nacional. El carácter inconcluso de las naciones latinoamericanas, junto con su condición dependiente, establecía una imposibilidad para que las dictaduras autóctonas desplegaran un perfil nacionalista y reivindicaran la autarquía y la soberanía nacional. A su vez, como señala Boron, esos mismos factores obstaculizaron la conformación de cualquier tipo de movimiento de masas que pudiera apoyar a los regímenes de facto.

Pues bien, hecha ya la síntesis de posiciones, para cerrar este trabajo, debemos decir que estas fecundas reflexiones sobre el autoritarismo, el Estado y lo político perderían vigor hacia la década de los ochenta, pues en ese entonces, las dictaduras militares dejarían de ser un objeto de estu- 
dio predominante en las ciencias sociales latinoamericanas. En el campo de la teoría política serían sucedidas, a causa de diversas razones, por otras temáticas. El principal motivo de ese viraje sería, sin dudas, el cambio rotundo en el contexto político. El inicio de las transiciones a la democracia plantearía nuevos problemas a los intelectuales latinoamericanos, quienes se abocarían más decididamente a analizar el problema de los regímenes políticos. Y entre ellos, en los años ochenta cobraría primacía el estudio de un régimen político en particular: la democracia.

Los procesos políticos latinoamericanos de comienzos del siglo XXI pusieron en discusión el problema de la democracia, aunque en términos muy diferentes a los establecidos en los años ochenta y noventa del siglo xx (caída del Muro de Berlín mediante). Más bien, los gobiernos que varios autores denominaron "posneoliberales" colocaron en primera plana el debate acerca del significado de la democracia, desplazando su sentido de aquel que aún resulta dominante en el mainstream de la ciencia política: el procedimental, ajustado estrictamente a su dimensión e ingeniería institucional.

Sin embargo, el viraje conservador en Argentina en 2015 (conseguido mediante un triunfo electoral), el golpe parlamentario ocurrido en Brasil en 2016 y el sismo político-económico que está atravesando Venezuela, han cambiado notoriamente el panorama de la región. Las clases dominantes han retornado con fuerza a la palestra del poder político y asumen un nuevo protagonismo. Ello cristaliza en un avance de las derechas en el campo político. A contrapelo de aquellos años ochenta donde, en su promedio, ya predominaba con claridad el debate sobre la democracia en América Latina, la actualidad de la región muestra un vuelco político que demanda un cambio vertiginoso en las prioridades de la discusión académica en materia de teoría política. Como en épocas muy oscuras de nuestra región, el autoritarismo ha retornado para colocarse otra vez en el centro del debate. Desde nuestro punto de vista, Agustín Cueva y su generación intelectual tienen mucho que enseñarnos al respecto. En ese sentido, este artículo espera haber colaborado, aunque sólo sea con un pequeño grano de arena, con la tarea de recuperar ese legado. 
BIBLIOGRAFÍA

BORON, ATILIO. "El fascismo como categoría histórica: en torno al problema de las dictaduras en América Latina". Estado, capitalismo y democracia. Buenos Aires: CLACSO, 2003. 30-74.

Cueva, Agustín. "Elementos y niveles de conceptualización del fascismo". Teoría social y procesos políticos en América Latina. México: Edicol, 1979a.

"La 'remodelación' fascista de la sociedad". Teoría social y procesos políticos en América Latina. México: Edicol, 1979b. 177187.

"La fascistización de América Latina". Teoría social y procesos políticos en América Latina. México: Edicol, 1979c.

. "América Latina en el último quinquenio: 1976-1980". Revista Araucaria de Chile 11 (1980): 7-18.

Garretón M., Manuel Antonio. Proyecto, trayectoria y fracaso de las dictaduras militares del cono sur: un balance. Santiago de Chile, FLACSO, 1982 (Documento de Trabajo 217, agosto).

GRAMSCI, ANTONIO. El materialismo bistórico y la filosofía de Benedetto Croce. Buenos Aires: Nueva Visión, 2003.

MARINI, RuY MAURO. Intervención en la mesa redonda "Las fuentes externas del fascismo". Cuadernos Políticos 18 (1978): 13-34.

O'Donnel, Guillermo. Apuntes para una teoría del Estado. Buenos Aires: CEDES-CLACSO, 1977.

TZEIMAN, ANDrés. Agustín Cueva: el pensamiento irreverente. Buenos Aires: Universidad Nacional de General Sarmiento, 2016.

ZavaleTA MERCADO, ReNÉ. "El fascismo y la América Latina". Clases sociales y conocimiento. La Paz: Los Amigos del Libro, 1988.

"Notas sobre fascismo, dictadura y coyuntura de disolución". El Estado en América Latina. La Paz: Los Amigos del Libro, 1990. $1-17$. 